\title{
A Better Look at Learning: How Does the Brain Express the Mind?
}

\author{
Frederic Perez-Alvarez ${ }^{1,2,3^{*}}$, Alexandra Perez-Serra ${ }^{4}$, Carme Timoneda-Gallart ${ }^{2,3}$ \\ ${ }^{1}$ Neuropediatric Unit, Hospital Universitari ICS Dr J Trueta, Girona, Spain \\ ${ }^{2} J P$ Das Developmental Centre, Alberta, Canada \\ ${ }^{3}$ Quality of Life Research Institute and Foundation Carme Vidal Educational Psychology, University of Girona, \\ Girona, Spain \\ ${ }^{4}$ Departmnet of Biology, Girona University, Girona, Spain \\ Email: *fperezalvarez@gmail.com
}

Received June 30 $0^{\text {th }}$, 2013; revised August $5^{\text {th }}, 2013$; accepted September $11^{\text {th }}, 2013$

Copyright $(2013$ F. Perez-Alvarez et al. This is an open access article distributed under the Creative Commons Attribution License, which permits unrestricted use, distribution, and reproduction in any medium, provided the original work is properly cited.

\begin{abstract}
Learning problems in the light of PASS assessment and intervention were studied. Data for 248 subjects with specific learning impairment (SLI), dyslexia, dyscalculia, and non-defined learning difficulty were studied. Hierarchical cluster analysis of PASS scores at baseline was performed. PASS re-assessment was carried out at 6 and 12 months after 6-month period of intervention. Four statistically different cluster groups were identified. All groups, except one, showed cognitive weakness. Planning weakness, associated with other weakness, appears involved in all groups except two where isolated planning and successive weaknesses were identified, respectively. SLI, dyslexia, and dyscalculia are not homogenous entities. A kind of dyslexia is clearly linked to isolated successive weakness. SLI-expressive (SLIe) and a minority of both dyslexia and dyscalculia appear linked to successive weakness although associated with planning and additionally with attention in the case of SLIe. SLI-expressive-receptive (SLIe-r) and Dyscalculia appear linked to simultaneous weakness, although associated with planning weakness. Other kind of SLIe-r appears linked to isolated planning weakness. Other types of SLIe-r and Dyscalculia appear liked to combined planning + successive + attention weakness. Isolated dysfunctional attention does not appear in any case. After 6 months of intervention, planning improves statistically in all cases. Attention improves in few cases. Successive and simultaneous do not improve. The best result is in dyslexia, SLIe and a minority of Dyscalculia. The worst result is in those without cognitive deficiency. The effect of intervention at 6 months remains with minor changes at 12 months after 6 months without intervention.
\end{abstract}

Keywords: Cognition; Learning; Dyslexia; Dyscalculia; PASS

\section{Introduction}

For years and years learning difficulties have been challenging for teachers, school psychologists, doctors, and other professionals in the field. Over years, multiple approaches have been carried out. Although many classifications have been reported, remediation continues to be a challenging point. Data regarding the etiology, academic outcome, and utility of interventions are either scarce or lacking. There are indications that adequacy in learning skills during childhood has an impact on future professional achievement.

Usually classifications (APS, 2000; Bishop, 1994; Bishop \& Leonard, 2001; Bravo, 1979; Maggiolo \& Pavez, 2000; Matute, Roselli, Ardila, \& Ostrosky-Solis, 2005; Rapin, 1998; Rapin \& Allen, 1983; Roselli-Cock et al., 2004; WHO, 1993) are based on descriptive categories delineating syndromic entities. In fact, we are dealing with a heterogeneous group of disorders manifested by significant difficulties in the acquisition and use of listening, speaking, reading, writing, reasoning or mathematical abilities. These disorders result from impairments in one or

\footnotetext{
"Corresponding author.
}

more psychological processes related to learning in combination with otherwise average abilities essential for thinking and reasoning. Usually, they are specific, not global, impairments and as such are distinct from intellectual disabilities. The term "psychological processes" describes an evolving list of cognitive functions. However, the underlying processes that account for these deficits are less clear. To date, research has focused on functions such as: phonological processing, memory and attention, processing speed, language processing, perceptual-motor and visual-spatial processing, executive functions (e.g., planning, monitoring, and meta-cognitive abilities), and so on.

These disorders are intrinsic to the individual and presumed to be due to central nervous system dysfunction. Even though a learning disability may occur concomitantly with other handicapping conditions (e.g., sensory impairment, mental retardation, social and emotional disturbance) or environmental influences (e.g., cultural differences, insufficient/inappropriate instruction, psychogenic factors), it is not the direct result of those conditions or influences. These entities, so classified, have proved to be useful for prognosis, but not so much for intervention because we are far from knowing the central neurological 
pathogenesis. Knowing this central mechanism will allow us to intervene in the genesis of the problem and not in the consequence of the problem, that is, the external sign or learning behavior that descriptive categories are based on.

There are children with global learning problem, with very low scores in all tests of IQ test. Other children have specific learning difficulties. If such children are given a IQ test, they score at least average intelligence although still have problem with learning. If a battery of tests were given to them they would score average to high on some of them and low on others. In summary, they have a severe delay in classroom achievement, and a significant discrepancy between intellectual ability and academic achievement, and a processing deficit that is linked to the delay in classroom achievement and significant discrepancy. They hear and see normally, but they have trouble with what they see and hear. These are pupils that need to be taught differently from the norm. Attention-deficit hyperactivity disorder (ADHD) is often studied in connection with learning disabilities, but it is not actually included in the standard definitions of learning disabilities (Perez-Alvarez, Serra-Amaya, \& Timoneda-Gallart, 2009). Deficits in any area of information processing can manifest in a variety of specific learning disabilities. It is possible for an individual to have more than one of these difficulties. This is referred to as comorbidity or co-occurrence of learning disabilities.

Many studies have shown that children with learning difficulties have poorer particular skills as compared to other skills. To date, most neuropsychological studies have focused on a limited number of cognitive variables. Specifically, many studies have been limited to evaluating overall level of intellectual functioning and focused on one area of cognitive development. Conclusions from prior studies are limited by multiple factors including small sample sizes, use of inadequate cognitive measures, the lack of control groups to assess the influence of practice effects, and the lack of assessment of both short- and long-term outcome. Whereas some patients may show early improvements in functioning, improvements are sometimes not noted until one year after the intervention. The reflections on these limitations serve as a basis for establishing directions for our research.

Since 1997 we count on the DN:CAS (Naglieri \& Das, 1997) to assess the PASS cognitive processing of information (Das \& Kendrick, 1997; Das, Naglieri, \& Kirby, 1994; Das, Kar, \& Parrilla, 1996; Das, Garrido, Gonzalez, Timoneda, \& PerezAlvarez, 1999). This is considered a useful measure for diagnostic testing in Pediatric Neurology (Swaiman, Ashwal, \& Ferriero, 2006). PASS is the acronym for planning, attention, successive, and simultaneous processes. Planning may be considered equivalent to executive function. Attention is equivalent to selective attention. Successive and simultaneous have to do with serial and relationship processing. The PASS states that the same clinical manifestation can be the result of different central processing (software) and different clinical manifestations can be the consequence of the same central processing. This principle is essential for understanding what we are referring to when we are dealing with cognitive assessment. Otherwise, we are mixing central processing with output and vice versa. In particular, attention as central processing must be differentiated from attention as external clinical manifestation or behavioral expression in the sense of being attentive to. In other words, not being attentive to the teacher (external behavioral pattern) is compatible with being attentive to (internal, central processing) what we keep in mind, for instance, the last interesting film. Therefore, a true attention test must be assessing internal central processing, but not only external behavioral attention. Likewise, inattentive behavior may be related with other dysfunctional cognitive processing different from attention. This way, a behavioral phenotype based on external manifestations is not exactly the same as a cognitive phenotype and we must assume that behavior is the consequence of mental processing but not vice versa.

The DN:CAS battery for assessing PASS processing is based on cerebral lesion studies (Das, Naglieri, \& Kirby, 1994; Das, Kar, \& Parrilla, 1996; Das, Garrido, Gonzalez, Timoneda, \& Perez-Alvarez, 1999; McCrea, 2009). That is, first neurological lesions were analyzed, then a theoretical framework was deduced, the principle of which is the central processing is independent of intake and output of information, and then the process of test creation was carried out. A relevant consequence is that every test is specific for a particular processing, and therefore no test assesses more than a cognitive function.

The four PASS processes are assessed using the Cognitive Assessment System (CAS) which was specifically built according to the PASS theory (Naglieri \& Das, 1997). There is a strong empirical base to support both the theory and its operationalization in the CAS. It was standardized on a sample of 2200 children aged 5 through 17 years who were representative of the USA population on a number of important demographic variables. The CAS full scale has a high internal reliability ranging from .95 to .97 for the different age groups. The average reliability coefficients for the scales are .88 for planning, .88 for attention, .93 for simultaneous, and .93 for successive (Naglieri \& Das, 1997; Naglieri \& Das, 1995).

The purpose and overall objective of this study were to investigate the learning difficulties in children at primary school (6 to 11 years old) in the light of PASS processes and to determine the usefulness of PASS intervention within the one year follow-up period. This study is oriented to support the idea that a PASS diagnosis may be very useful to intervene any learning problem independently of the category we are dealing with. The direct way to assess the effects of treatments on functioning is through pre- and post-treatment assessment. It was predicted (hypothesis) that some PASS cognitive functions will be treatment sensitive while others will be relatively treatment independent after intervention. It was also intended to verify longterm effect of intervention on cognitive function in terms of the PASS processes.

\section{Methodology}

\section{Subjects}

Subjects were recruited from the pediatric neurology practice by direct contact. If the subject or his/her family was interested in participation, the principal investigator conducted a face-toface interview to explain all aspects of the research as documented on the consent form. Signed parental consent form was required. Consent was obtained by the principal investigator, witnessed by a member of the staff. A copy of this form was then given to the participant, and the original was kept with the patient's data file. Ethical approval was granted.

Each child had been clinically referred because of learning difficulties, therefore with low academic achievement. Teachers were asked to provide information on achieving, reading, writing, mathematics (Bravo, 1979). Among the children, there 
were cases of difficulties in expressive and receptive speech as well as in reading and writing o math. Children experiencing learning/reading difficulties due to emotional, behavioral, and/or medical condition as indicated by the school record were not included in the study.

First of all, WISC-R was given and an IQ equal o superior to 80 was considered to be acceptable. Then, the children were identified by using a 2 -stage screening process. In the first stage, the teachers of the children were interviewed by two blindedresearchers and each of the subjects was assessed with respect to the following questions. Concerning language impairment, whether expressive or mixed receptive-expressive, language comprehension, disfluency of speech, short and laboriously produced utterances, impaired phonology as omissions, substitutions and distortions of speech sounds, distortions of consonants and consonants clusters in all word positions, production of unpredictable and unrecognizable sounds making speech impossible to understand, atypical grammar, not merely delayed, telegraphic speech. Concerning dyslexia (Maggiolo \& Pavez, 2000), problems in speaking like mispronunciation of long or complicated words, non-fluent speech, use of imprecise language, problems in reading like very slow progress in acquiring reading skills, trouble reading unknown or unfamiliar words that must be sounded out, inability to read small "function" words, choppy and labored oral reading, disastrous spelling, very slow and tiring reading, extreme difficulty learning a foreign language. In particular, the following phonological tasks were carried out: rhyme oddity, syllable completion, initial phoneme identification, onset oddity, single phoneme onset oddity, and phoneme elision. Concerning dyscalculia, according to age, difficulties involving early math skills, the meaning of numbers, learning to count or matching them with amounts, difficulties sorting objects by shape size or color, slower at developing math, problems with basic math skills as adding, subtracting, multiplying and dividing, trouble telling time, chronology, sequencing events, remembering schedules or following directions, difficulty with his/her sense of direction, rendering him/her disoriented, how he/she handles the concept of money, he/she can't grasp abstract concepts as coins, bills, credit, budgeting or financial planning, difficulty with games that require strategy or keeping score, difficulty with math abilities as estimating quantities, figuring out change or counting days to an event.

If person being evaluated fulfill half or more of these questions, he/she was formally recruited to be formally tested. An interobserver agreement of $80 \%$ was required as inclusion criterion. Those selected underwent phase 2 evaluation according to the following tests. All tests were administered with the permission given by the parents. Oral language subtests, assessing either expressive or receptive (comprehension), of the validated Evaluación Neuropsicológica Infantil battery (Matute et al., 2005; Roselli et al., 2004); those scoring in the lowest $20 \%$ on these tests were classified as SLI. Translated but not standardized Word Attack and Word Identification of the Woodcock Word Reading task; reading scores at or below the $25^{\text {th }}$ percentile on both tests were required for dyslexia category. Translated normalized arithmetic battery that includes questions on number comprehension, production, and calculation (McCloskey et al., 1985; Shalev et al., 1998) was used for dyscalculia; those scoring in the lowest $5^{\text {th }}$ percentile of the normative group were identified as having dyscalculia. All of them were administered SNAP-IV and the translated, back-translated and validated
Strengths and Difficulties Questionnaire (SDQ) in order to rule out ADHD and comorbidity.

After the screening process, 71 were classified as mixed Expressive and Receptive Specific Language Impairment (SLIe-r), 30 as Expressive Specific Language Impairment (SLIe), 66 as Dyslexia (Dysl), and 59 as Dyscalculia (Dysc). 22 were classified as Nonspecific Category because they did not meet criteria for any of the categories above (Table 1). Those identified as Language Impairment correspond to the former dysphasia category. The distinction between developmental dysphasia on the one hand and dyslexia on the other is perhaps the hardest in terms of phonological processing, but we must remark our subjects were recruited such that each category did not meet criteria of the other ones.

The sample included 248 children, boy/girl ratio 4:1, aged 6 to 11 years (primary-elementary school), 41 subjects for each age group except two strata with $42,90 \%$ of them were righthanded, $10 \%$ left-handed or ambidextrous. The study population reflects the demographics of the pediatric population at the region and it is in accordance with learning disabilities affecting an estimated $5 \%$ to $15 \%$ of children in the normal school population. All of them were with native language proficiency. The children came from middle class families. The sample was WISC performance IQ $=90, \mathrm{SD}=18.2$ and verbal $\mathrm{IQ}=81.4$, $\mathrm{SD}=16.1$. This sample was recruited from clinical setting. The subject population was readily available from the very large pediatric neurology practice at our institution. Those with any neurological disorder, psychiatric disorder, sensory disorder like hearing impairment, any known syndrome like Angelman syndrome and others were excluded from the study to reduce any confounding factors. All children were screened for vision, and hearing. If necessary, additional medical examination was ordered and investigations by audiologists, neurologists, psychologists were carried out as needed. Any previous medication or therapy was also ruled out.

\section{Instrument}

All subjects $(\mathrm{n}=248)$ were administered translated and validated for local population DN:CAS (Das Naglieri Cognitive Assessment System) battery at baseline, and at months 6 and 12 of follow-up period. Intervention was over 6 months. No intervention between 6 and 12 months. The $6 \mathrm{mo} / 12$ mo follow-up allows us to rules out the potential "practice effect" of two

Table 1.

Distribution of learning problems according to cluster analysis.

\begin{tabular}{|c|c|c|c|c|c|}
\hline & Cluster 1 & 2 & 3 & 4 & Total \\
\hline SLIe-r & 38 & 20 & & & 71 \\
\hline SLIe-r + Dysc & & $13+12$ & & & \\
\hline Dysc & 25 & 17 & & & 59 \\
\hline Dysc + SLIe + Dysl & & & $5+30+5$ & & \\
\hline SLIe & & & & & 30 \\
\hline Dysl & & & 61 & & 66 \\
\hline Non-specific & & & & 22 & 22 \\
\hline Total & & & & & 248 \\
\hline
\end{tabular}

Note: SLIe-r: expressive-receptive SLI; SLIe: expressive SLI; Dysc: dyscalculia; Dysl: dyslexia. 
closely spaced psychological tests. Subjects were run individually over five sessions. Sessions lasted on average 30 minutes, though subjects were allowed to take breaks or discontinue the sessions whenever they desired. The test administration was individual, over a three-month period for baseline.

The battery (Naglieri \& Das, 1997) assesses PASS processing, namely, planning, attention, successive and simultaneous. Tests of planning are: Matching Numbers, Planned Codes, and Planned Connections. Those of attention are: Expressive Attention, Number Detection, and Receptive Attention. Simultaneous tests are: Nonverbal Matrices, Verbal-Spatial Relations, and Figure Memory. Successive ones are: Word Series, Sentence Repetition, Sentence Question (from 8 to 17 years) and Successive Speech Rate (from ages 5 to 7 years). Each of the four PASS scales yields a standard score with a normative mean of 100 and a standard deviation (SD) of 15 . For three subtests in each of the four scales, the mean is 10 and the SD is 3 .

Matching Numbers requires children devise a strategy to find and underline two numbers that are the same in a row. The numbers increase in length form one digit to seven digits. Planned Codes show distinct set of codes and arrangements of rows and columns. A legend at the top of each page shows how letters correspond to simple codes (e.g. A,B,C,D correspond to $\mathrm{OX}, \mathrm{XX}, \mathrm{OO}, \mathrm{XO}$, respectively). Children must fill in the appropriate codes in empty boxes beneath each letter in any efficient manner (plan). Planned Connections requires children to efficiently connect numbers in sequence or numbers and letters in alternating orders. Expressive Attention demands children to name the color ink the words, Blue, Yellow, Green, and Red are printed in according to Stroop phenomenon. Number Detection consists of pages of numbers in different formats. Children are required to find, for instance, numbers 1,2 , and 3 on a page containing many distractors (e.g. the same number printed in different font). The child's performance is timed and it takes into account accuracy (correct minus false detections). Receptive Attention demands the child identify letters' pairs that meet specified criteria among many letters pairs that do not. Nonverbal Matrices shows shapes and geometric designs that are interrelated through spatial or logical organization. VerbalSpatial Relations shows drawings and a printed question; for instance, "Which picture shows a circle to the left of a cross under a triangle above a square?" Figure Memory requires the child identify a geometric design when it is embedded in a complex figure. Word Series demands the child repeat words in the same order as stated by the examiner. Sentence Repetition requires the child repeat sentences, such as "The blue is yellowing" that are read aloud by the examiner. Sentence Questions (for those in age from 8 to 17 years) uses the same previous sentences, but in different manner. Children are read a sentence and then asked a question about the sentence. For example, the sentence: "The blue is yellowing". The question: "Who is yellowing?" The answer: "The blue." Successive Speech Rate requires the child to repeat a series de words in particular linear order.

\section{Procedure}

All tests were administered by trained technical staff who were blinded to conditions of treatment. All tests proposed for use in this study are reliable and valid measures of cognitive functioning and are commonly used in practice and research. There are no known risks associated with the cognitive testing procedures except fatigue and frustration. In order to minimize this, where age appropriate, frequent breaks in the testing or separate serial testing sessions were be planned. The risks to the subjects in undergoing cognitive tests are very minimal, and may not exist at all, other than the potential for fatigue and the time lost in undergoing testing. Instead, potential benefits to individual subjects include the identification of cognitive deficits that might help in maximizing school interventions.

The intervention sessions (Das \& Kendrick, 1997) were applied to individual. Each child received 15 sessions of 45 minutes over a period of 6 months. After the intervention they were tested again. 6 months later, without further intervention, they were tested again. The PREP is founded on the premise that the transfer of principles can be facilitated through inductive rather than deductive inference. The program is structured so that tacitly acquired strategies are likely to be used in appropriate ways. Children are encouraged to engage in discussions, both during and following their performance. Each task is designed to develop strategies. Thus children develop their ability to use these strategies through experience with the task. Children are encouraged to become aware of the use of strategies through verbalization. Both "near transfer" and "far transfer" take place over the course of remediation.

The program consists of ten tasks. Each task involves both a non-reading global training component and a curriculum-related bridging component. Both of them require the application of simultaneous or successive strategies, providing children with the opportunity to internalize strategies in their own way, thus facilitating transfer. The global tasks begin with content that is familiar and non-threatening. Complexity is introduced gradually. The global and bridging components are further divided into three levels of difficulty. A system of prompts is integrated into each global and bridging component. Thus the tasks are completed with a minimal amount of assistance and a maximal amount of success. A criterion of $80 \%$ correct responses is required before a child can proceed to the next level of difficulty. To summarize briefly, PREP is a program that aims at improving the information processing whatever the specific task involved.

The PASS scores were subjected to a hierarchical clustering method (SPSS v. 13.0) in order to see whether the sample was homogeneous or heterogeneous in regard to cognitive processing (Aldenderfer \& Blashfield, 1984). Baseline PASS cognitive scores were compared to 6 and 12 months follow-up scores. Analysis of variance (MANOVA), Scheffe test, and paired Student t-test with effect size statistic (Cohen's $\delta$ ) was applied where appropriate.

\section{Results}

Four clusters described those groups in which the degree of association is high between the members of the same group and low between members of different groups. Tables 1 and $\mathbf{2}$ show the four group resolution. With groups of this size, we have statistical power to detect a difference between groups. The four clusters differed significantly from each other in $\operatorname{MANOVA}\left(\mathrm{F}_{(246)}=615 ; p<.01\right)$.

As Tables 1-3 show, 4 clusters are identified and they differ from each other. The cluster 4 differs from the rest in that there is no PASS dysfunction. The rest of the clusters show PASS dysfunction. They have in common planning dysfunction except in sub-cluster 3.2 corresponding to Dysl where there is 
Table 2.

Distribution of cases and PASS profiles, according to cluster analysis.

\begin{tabular}{|c|c|c|c|c|}
\hline Cluster groups & $\mathbf{N}$ & Cluster & Sub-groups (n) & PASS (mean under $85 \pm$ SD $^{*}$ \\
\hline \multirow[t]{5}{*}{1} & 63 & 1.1 (SLIe-r) & 38 & $\mathrm{P}<\mathrm{A}<\mathrm{Su}$ \\
\hline & $\left(25.40 \%{ }^{* *}\right)$ & & & $77 \pm 07 \quad 79 \pm 09 \quad 82 \pm 10$ \\
\hline & & 1.2 (Dysc) & 25 & $\mathrm{P}<\mathrm{Su}<\mathrm{A}$ \\
\hline & & & & $76 \pm 11 \quad 80 \pm 08 \quad 84 \pm 11$ \\
\hline & & Total & 63 & \\
\hline \multirow[t]{9}{*}{2} & 62 & \multirow[t]{2}{*}{2.1 (SLIe-r) } & 20 & $\mathrm{P}$ \\
\hline & $(25.0 \%)$ & & & $78 \pm 13$ \\
\hline & & \multirow[t]{2}{*}{2.2 Dysc) } & 17 & $\mathrm{Si}<\mathrm{P}$ \\
\hline & & & & $80 \pm 11 \quad 83 \pm 07$ \\
\hline & & \multirow[t]{2}{*}{2.3 (SSLIe-r + Dysc) } & 25 & $\mathrm{P}<\mathrm{Si}$ \\
\hline & & & & $77 \pm 12 \quad 82 \pm 10$ \\
\hline & & & 13 (SLIe-r) & \\
\hline & & & 12 (Dysc) & \\
\hline & & Total & 62 & \\
\hline \multirow[t]{10}{*}{3} & 101 & $3.1($ SLIe + Dysc + Dysl) 40 & & \multirow[b]{2}{*}{$\mathrm{Su}<\mathrm{P}<\mathrm{A}$} \\
\hline & $(40.72 \%)$ & & 30 (SLIe) & \\
\hline & & & & $77 \pm 11 \quad 79 \pm 11 \quad 82 \pm 09$ \\
\hline & & & 5 (Dysc) & $\mathrm{P}<\mathrm{Su}$ \\
\hline & & & & $75 \pm 13 \quad 80 \pm 12$ \\
\hline & & & 5 (Dysl) & $\mathrm{Su}<\mathrm{P}$ \\
\hline & & & & $78 \pm 10 \quad 82 \pm 14$ \\
\hline & & 3.2 (Dysl) & 61 & $\mathrm{Su}$ \\
\hline & & & & $79 \pm 10$ \\
\hline & & Total & 101 & \\
\hline \multirow[t]{2}{*}{4} & 22 & & \multirow{2}{*}{\multicolumn{2}{|c|}{ No PASS cognitive deficiency }} \\
\hline & $(8.87 \%)$ & & & \\
\hline Total & $248(100 \%)$ & & & \\
\hline
\end{tabular}

Note: ${ }^{*}$ Avarage across subjects; ${ }^{* *} \%$ of total. PASS profile: $\mathrm{P}=$ planning $\mathrm{A}=$ attention $\mathrm{Su}=$ Successive $\mathrm{Si}=\mathrm{Simultaneous.} \mathrm{SLIe-r:} \mathrm{specific}$ learning impairment, expressive and receptive SLIe: specific learning impairment expressive Dysc: dyscalculia Dysl: dyslexia.

Table 3.

Comparison of cluster groups on PASS processing according to Scheffe test.

\begin{tabular}{ccc}
\hline PASS & Cluster group differences & P Scheffe \\
\hline Planning & 1, 2, and 3 lower than 4 & $<0.001$ \\
Attention & 1 lower than the other 3 groups & $<0.01$ \\
Successive & 3 lower than the other 3 groups & $<0.01$ \\
Simultaneous & 2 lower than the other 3 groups & $<0.001$ \\
\hline
\end{tabular}

only successive dysfunction, but they differ from each other in associated dysfunctions except in cluster 2, sub-cluster $2.1(\mathrm{n}=$ 20) corresponding to SLIe-r where planning dysfunction is isolated and non-associated. Thus, we find planning + attention + successive dysfunctions in cluster 1 where we can identify SLIe-r $(n=38)$, and Dysc $(n=25)$. In cluster 2 we find isolated planning corresponding to SLIe-r $(\mathrm{n}=20)$ versus planning + simultaneous corresponding to Dysc $(=17)$, and SLIe-r + Dysc $(\mathrm{n}=25)$. Finally, in cluster 3 planning + successive corresponding to Dysc $(\mathrm{n}=5)$ and Dysl $(\mathrm{n}=5)$ versus planning + successive + attention corresponding to SLIe $(n=30)$. In other words, planning is the PASS processing more frequently dys- functional in learning difficulties whatsoever, although it is usually associated with other dysfunctions. Only in cluster 2, sub-cluster $2.1(\mathrm{n}=20)$ corresponding to SLIe-r there is isolated planning dysfunction. Instead, only in sub-cluster 3.2, pertaining to cases of dyslexia $(\mathrm{n}=61)$, planning is not involved (instead, isolated successive is involved).

In summary, the Nonspecific Category of learning difficulties $(n=22)$ in cluster 4 is clearly defined. We postulate they do not have cognitive deficiency (maybe, emotional problem) or instead they have a cognitive deficiency not detected by PASS. On the other hand, we can see SLI, dyslexia, and dyscalculia are not homogenous entities in PASS terms. A kind of 
dyslexia is clearly liked to isolated successive dysfunction as we can see in cluster 3 , sub-cluster $3.2(n=61)$. In cluster 3 , SLIe $(n=30)$ and a minority of Dysc $(n=5)$ appear linked to successive dysfunction, although associated with planning dysfunction, and attention dysfunction in the case of SLIe $(n=30)$. We postulate its common dysfunction has to do with phonological dysfunction. In cluster 2, SLIe-r $(\mathrm{n}=13)$ and Dysc $(\mathrm{n}=$ $17+12$ ) appear linked to simultaneous dysfunction, although associated with planning dysfunction. On the other hand in cluster 2, subcluster 2.1, another SLIe-r $(n=20)$ appears linked to isolated planning dysfunction. In cluster 1, other type of SLIe-r $(\mathrm{n}=38)$ and Dysc $(=25)$ appear liked to combined planning + successive + attention dysfunction. We must remark isolated dysfunctional attention does not appear in any case.

Finally, PASS assessment 6 months after intervention, and assessment at 12 months from baseline after 6 months without intervention are shown in Tables $\mathbf{4}$ and $\mathbf{5}$.

We can see the effect of intervention at 6 months remains at 12 months with minor changes after 6 months without intervention. We must remark that planning, which is dysfunctional in all cases apart from in sub-cluster 3.2 (Dysl), is the PAS dysfunction more susceptible (sensitive) to intervention. Therefore, all categories can ameliorate with PASS intervention because planning amelioration involves academic achievement improvement. Particularly, the best result corresponds to cluster 3, namely, SLIe $(\mathrm{n}=30)+$ Dysc $(\mathrm{n}=5)+$ Dysl $(\mathrm{n}=5)[\mathrm{p} /$ Cohen's $\delta, 0.001 / 0.9]$ and Dysl $(\mathrm{n}=61)[\mathrm{p} /$ Cohen's $\delta, 0.001 / 1.5]$. That is, we can expect the best response to intervention in these categories. The worst result is in cluster 4, that is, those with no PASS deficiency at all. Within those with PASS deficiency, the worst result is in cluster 2, namely, SLIe-r $(\mathrm{n}=20)[\mathrm{p} /$ Cohen's $\delta$,
0.05/0.5], Dysc $(\mathrm{n}=17)[\mathrm{p} /$ Cohen's $\delta, 0.04 / 0.4]$, and SLIe-r + Dysc $(\mathrm{n}=25)[\mathrm{p} /$ Cohen's $\delta, 0.04 / 0.4]$. In other words, some SLIe-r, and some Dysc show the most serious learning difficulties. These SLIe-r and Dysc subjects are different from those included in the cluster 1 . Those in cluster 1 , SLIe-r $(\mathrm{n}=38)$ [p/Cohen's $\delta, 0.02 / 0.6]$ and Dysc $(\mathrm{n}=25)[\mathrm{p} /$ Cohen's $\delta$, $0.03 / 0.5]$ respond better than those previously commented. However these ones show worse results than those in cluster 3, as we have said above. In other words, within SLIe-r and Dysc subjects we identify two types with different degree in difficulties.

Apart from planning, only PASS attention appears sensitive to intervention, with amelioration particularly better in cluster 1 , and worse in cluster 3 . On the contrary, both successive and simultaneous remain insensitive to intervention.

\section{Discussion}

This study was designed to explore learning difficulties, in particular what we call specific language impairment, dyslexia and dyscalculia, in the light of PASS assessment and intervention. The key question is which central processing we are assessing with the tests being used in the studies dealing with learning difficulties. In other words, can the tests be really measuring different central processes of information? The answer is given by the process involved in the creation of the test, that is, the process is the product. Therefore, both reliability in the sense of consistency, and validity in the sense of accuracy depend on this concept. Furthermore, both sensitivity and specificity are also influenced by this construct process. We are used to seeing that a particular test is assumed to measure several

Table 4.

Differential improvement in PASS scores after 6 months of intervention.

\begin{tabular}{|c|c|c|c|c|c|c|c|c|}
\hline & \multicolumn{2}{|c|}{ Cluster 1} & \multicolumn{3}{|c|}{ Cluster 2} & \multicolumn{2}{|c|}{ Cluster 3} & \multirow{2}{*}{$\begin{array}{l}\text { Cluster } 4 \\
n=22\end{array}$} \\
\hline & $\begin{array}{c}\text { SLIe-r } \\
\mathrm{n}=38 \\
\mathrm{P}<\mathrm{A}<\mathrm{Su}\end{array}$ & $\begin{array}{c}\text { Dysc } \\
\mathrm{n}=25 \\
\mathrm{P}<\mathrm{Su}<\mathrm{A}\end{array}$ & $\begin{array}{l}\text { SLIe-r } \\
\mathrm{n}=20 \\
\mathrm{P}\end{array}$ & $\begin{array}{c}\text { Dysc } \\
\mathrm{n}=17 \\
\mathrm{Si}<\mathrm{P}\end{array}$ & $\begin{array}{l}\text { Comb } \\
\mathrm{n}=25 \\
\mathrm{P}<\mathrm{Si}\end{array}$ & $\begin{array}{l}\text { Comb } \\
n=40 \\
\mathrm{Su} / \mathrm{P} / \mathrm{A}\end{array}$ & $\begin{array}{c}\text { Dysl } \\
\mathrm{n}=61 \\
\mathrm{Su}^{*}\end{array}$ & \\
\hline Planning & $0.02 / 03$ & $0.03 / 0.5$ & $0.05 / 0.5$ & $0.04 / 0.4$ & $0.04 / 0.4$ & $0.001 / 0.9$ & $0.001 / 1.5$ & $0.05 / 0.2^{* *}$ \\
\hline Attention & $0.03 / 0.3$ & $0.04 / 0.2$ & NS & NS & NS & $0.05 / 0.2$ & $0.05 / 0.2$ & NS \\
\hline Successive & NS & NS & NS & NS & NS & NS & NS & NS \\
\hline Simultaneous & NS & NS & NS & NS & NS & NS & NS & NS \\
\hline
\end{tabular}

Note: "Cognitive weakness at baseline: an individual PASS (planning, attention, successive, simultaneous) score lower than the child's mean and below normative standard score $85 . \mathrm{P}=$ planning $\mathrm{A}=$ attention $\mathrm{Su}=$ successive $\mathrm{Si}=$ simultaneous Comb in cluster 2 is SLIe + Dysc Comb in cluster 3 is $\mathrm{SLIe}+$ Dysc + Dysl. ${ }^{* *} p$ paired $\mathrm{Student}$ $\mathrm{t}$-test/effect size as average across subjects. Statistical effect size according to Cohen's $\delta$ : trivial $(<0.1)$, small $(0.1-0-3)$, moderate $(0.3-0.5)$, large difference effect $(>0.5)$.

Table 5.

Differential improvement in PASS scores at 12 months assessment, 6 months after intervention.

\begin{tabular}{|c|c|c|c|c|c|c|c|c|}
\hline & \multicolumn{2}{|c|}{ Cluster 1} & \multicolumn{3}{|c|}{ Cluster 2} & \multicolumn{2}{|c|}{ Cluster 3} & \multirow{2}{*}{$\begin{array}{c}\text { Cluster } 4 \\
n=22\end{array}$} \\
\hline & $\begin{array}{c}\text { SLIe-r } \\
\mathrm{n}=38 \\
\mathrm{P}<\mathrm{A}<\mathrm{Su}\end{array}$ & $\begin{array}{c}\text { Dysc } \\
\mathrm{n}=25 \\
\mathrm{P}<\mathrm{Su}<\mathrm{A}\end{array}$ & $\begin{array}{c}\text { SLIe-r } \\
\mathrm{n}=20 \\
\mathrm{P}\end{array}$ & $\begin{array}{c}\text { Dysc } \\
n=17 \\
\mathrm{Si}<\mathrm{P}\end{array}$ & $\begin{array}{l}\text { Comb } \\
\mathrm{n}=25 \\
\mathrm{P}<\mathrm{Si}\end{array}$ & $\begin{array}{l}\text { Comb } \\
\mathrm{n}=40 \\
\mathrm{Su} / \mathrm{P} / \mathrm{A}\end{array}$ & $\begin{array}{c}\text { Dysl } \\
\mathrm{n}=61 \\
\mathrm{Su}^{*}\end{array}$ & \\
\hline Planning & $0.03 / 06$ & $0.04 / 0.5$ & $0.05 / 0.5$ & $0.05 / 0.4$ & $0.04 / 0.4$ & $0.001 / 0.9$ & $0.001 / 1.5$ & $0.04 / 0.2^{* *}$ \\
\hline Attention & $0.03 / 0.3$ & $0.04 / 0.2$ & NS & NS & NS & $0.05 / 0.2$ & $0.05 / 0.2$ & NS \\
\hline Successive & NS & NS & NS & NS & NS & NS & NS & NS \\
\hline Simultaneous & NS & NS & $\mathrm{NS}$ & $\mathrm{NS}$ & NS & $\mathrm{NS}$ & NS & NS \\
\hline
\end{tabular}

Note: ${ }^{*}$ Cognitive weakness at baseline: an individual PASS (planning, attention, successive, simultaneous) score lower than the child's mean and below normative standard score $85 . \mathrm{P}=$ planning $\mathrm{A}=$ attention $\mathrm{Su}=$ successive $\mathrm{Si}=$ simultaneous Comb in cluster 2 is SLIe + Dysc Comb in cluster 3 is SLIe + Dysc + Dysl. ${ }^{* *} p$ paired Student $\mathrm{t}$-test/effect size as average across subjects. Statistical effect size according to Cohen's $\delta$ : trivial $(<0.1)$, small $(0.1-0.3)$, moderate $(0.3-0.5)$, large difference effect $(>0.5)$. 
considered different cognitive functions. So, for instance, Stroop and Trail Making tests are considered valid to assess both attention and executive function.

We must say that the majority of tests have been created according to a process consisting of seeing an external behavior (for instance, being attentive), then elaborating the test, and then normalizing it statistically. We can assume such test measures a behavior consequence of a central processing of information, but which central processing? For example, inattentive behavior involves the attention processing when mental activity is focused on another someone/something, for instance the last film. Then, we must differentiate attention central processing from attentional behavior. In fact, this may explain, to a great part, the heterogeneity of the results of the studies.

In PASS terms (Naglieri \& Das, 1997; Das, Kar, \& Parrilla, 1996; Das, Naglieri, \& Kirby, 1994; Das, Garrido, Gonzalez, Timoneda, \& Perez-Alvarez, 1999), four programs (software) are always working whenever any cognitive activity takes place independently of how the information is either entering (input) or leaving (output) central nervous system. In fact, this is not different from what the central nervous system (CNS) does with any kind of information being processed. For instance, ataxia must be considered a behavior (output) that can be due to failure in cerebellar neuronal network (program), but also in vestibular neuronal network (program). The same output can be due to different central programs. Really, something not different from the fact that different sums (programs) can actually produce the same sum (output) like $3+3,4+2,1+5=6$. Instead, different outputs can be due to the same central processing or program. This concept of mental cognitive operation allow us to intervene, for instance, on a dyslexic problem without using reading as a training material, because the central program is independent of input and output.

What can be deduced from neurological lesion studies is being reinforced by growing neurological evidence by using functional neuroimage (Cabeza \& Nyberg, 2000; Catani, Jones, \& Fytche, 2005; Davis et al., 2007; Hampson, Peterson, Skudlarski, Gatenby, \& Gore, 2002; Greicius, Krasnow, Reiss, \& Menon, 2003; Le Bihan et al., 2001; Maldjian, 2001; Morgane, Galler, \& Mokler, 2005; Perez-Alvarez \& Timoneda, 2007; Pujol et al. 2008; Raichle, 2000, 1991; Shinkareva et al. 2008; Vannest, Karunanayaka, Schmithorst, Szaflarski, \& Holland, 2009; Vuilleumier \& Pourtois, 2007). For years it has been well known the information enters via the senses, is centrally processed at neurological centers, and leaves via the motor system with verbal or non-verbal expression (manipulation). In turn, the central neurological centers constitute a serial network from the sensorial input to the motor output with the higher processor in between (Davis et al., 2007; Mesulam, 1998; Swanson, 2007; Swanson, Grant, Hökfelt, \& Jones, 2007). The PASS processing must be considered a processor at the higher central level.

Functional neuroimage techniques are allowing us to observe the central processing and distinguish peripheral sensorial network from central high-order network. In this sense, for instance, studies of language have been clearly illustrative, demonstrating how both receptive-perceptive areas (Wernicke) and expressive-motor areas (Broka) can be differentiated from central high-order areas. Broca area operates even in the case of silent reading, which means that Broca's neurons are successively placed in the processing network before the somatic neurons responsible for motor act of speaking out.
Functional neuroimage techniques of connectivity (Greicius, Krasnow, Reiss, \& Menon, 2003; Hampson, Peterson, Skudlarski, Gatenby, \& Gore, 2002; Maldjian, 2001; Swanson, 2007) as well as neuroimaging tractography (Catani, Jones, \& Fytche, 2005; Le Bihan et al., 2001) are allowing us to observe concrete neurological networks. The existence of a functional connection between Broca's area and Wernicke's area has been demonstrated at rest. An increase in this functional connection when the language system is actively engaged (when subjects are continuously listening to narrative text) has been also confirmed. A correlation between Broca's area and a region in left premotor cortex has been found to be significant at rest and to increase during continuous listening. These findings suggest that the neuroimage technology can reveal the presence and strength of functional connections in high-level cognitive systems (Hampson, Peterson, Skudlarski, Gatenby, \& Gore, 2002).

Also, neuroimage (Cabeza \& Nyberg, 2000, Raichle, 2000, 1991 ) is contributing to support the PASS principle that input and output of information are independent of central processing. For instance, both a complex mental arithmetic task and a task consisting of strategic searching of a missing card within a pack of cards activate dorsolateral prefrontal cortex. Two apparent different tasks are resolved by the same neuronal area. On the contrary, two tasks like which number is between 3 and 5 and which day is between Monday and Wednesday behave differently. These two apparently similar tasks do not activate the same neurological areas. The first task activates left parietal, whereas the second one does non-parietal area. Then, what our external observation tells us is different from or equal to is not always the same in the eyes of the neuron.

Multiple studies based not only on functional neuroimage but also on acoustic analysis of temporal processing of information (Perez-Alvarez, Fabregas, \& Timoneda, 2009; Tallal, Miller, \& Fitch, 1993) and on other methods have conclusively shown that central processing is independent of input and output of information, just as the essential principle of the PASS theory affirms. Similar evidence has been obtained with many different tasks, namely, mathematics, reading, music and so on, which allows us to deduce similar central programs operate independently of the nature of the task. We can observe input and output, but we must deduce the central processing. Input and output, either verbal or manipulative, may be both successive and simultaneous. Both input and output may be successive or simultaneous and, instead, central processing be simultaneous or successive respectively. Vice versa is also true.

Coincidentally, PASS mathematical factorial analysis validation (Das, Kar, \& Parrilla, 1996; Das, Naglieri, \& Kirby, 1994) tells us: "A is higher than B, B is higher than C. Which one is higher? Which one lower?" is resolved by using PASS simultaneous processing. Instead, " $\mathrm{A}$ is higher than $\mathrm{B}, \mathrm{C}$ is higher than A, B is higher than C. True or false?" is resolved by using PASS planning. Also, to get to reach a toy that is far away behind an obstacle by removing the obstacle and pulling the fabric where the object is placed is a behavior a 9 months old infant can do. We can see this behavior involves some kind of strategy, but it has been scientifically (factorial analysis) verified this action does not demand PASS planning, a processing that is not operative before 5 years old.

Another neurological principle is that the more central (higher processor), the less concentration of neurons (Vannest, karunanayaka, Schmithhorst, Szaflarski, \& Holland, 2009). In fact, this is in accordance with what was years ago demon- 
strated by using electrical stimulation of neurons in conscious patients being operated because of lesion in brain. Since Penfield we know with local anesthesia it is possible to test which effect on language follows after the stimulation in different areas of the brain. Therefore, although each PASS processing has been associated with particular centers, namely, planningprefrontal, attention-prefrontal/reticular system, successiveprefrontal/temporal, simultaneous-parietal/occipital (Das, Kar, \& Parrilla, 1996; Das, Naglieri, \& Kirby, 1994; McCrea, 2009), the fact is that every processing woks as a high-order one with a network distributed throughout the cortex. Thus, fMRI and Event Related Potential studies demonstrate that neurological processing is a complex process that cannot be related to a single brain regions, but rather it implicates an interactive network with distributed interactive activity in time and space (Morgane, Galler, \& Mokler, 2005; Vuilleumier \& Purtois, 2007). According to Cajal's law of neural avalanche, "every peripheral impression received by the dendrites (sensory) of a single cell is propagated towards the centers in the fashion of an avalanche; or, in other words, the number of neurons concerned in the conduction increases progressively from the periphery to the cerebrum". Likewise, evidence on oscillatory synchrony tells us that different neurological regions work in the coordination of long-distance neuronal communication during higher cognitive processes (Sederberg, Kahana, Howard, Donner, \& Madsen, 2003).

Having argued such a conceptual explanation, the next crucial point is the result in a test (or academic task) can be modified for better according to the central program is being used. Then, the intervention must focus on the central program, but not on the result. For instance, be the task to remember the input 633435. The same subject with dysfunctional successive may do it: a) by recalling the series with no other association ( relationship) but only the lineal association, one digit after the following (successive), something like rote memorization; b) by recalling it as 633435 , in which case you are using the successive for recording three units, that is, $63 / 34 / 35$, but each unit has been mentally elaborated with simultaneous, which allows us to establish the relationship $6+3=63$; c) by recalling it with the following strategy (planning): $63 / 34 / 35$ is as if 34,35 and 36 in consecutive order, but turning 36 into 63 and translating the last unit to the first one in the series. It is evident that our dysfunctional successive subject needs options (b) and (c). According to this, the same subject will produce different IQ result depending on which processing is operating each time.

Terms as phonologic processing, both receptive and expressive language processing, vocabulary processing, semantic processing, syntactic processing, phonologic processing, pragmatic processing, discourse processing, auditive discrimination, visual perception, number processing, arithmetic processing, music processing, auditive memory, verbal memory, visual memory, short term memory, long term memory, episodic memory, biographic memory, and so on can all be accounted for in the light of PASS cognitive processing (Figure 1) The PASS processes are not memories, but memory works using the PASS processes. The matter is that these terms are defined by the input of information.

We can explain how learning happens by understanding how information processing takes place. We assume this conceptualization is crucial for a efficient intervention. The most simple learning, consisting of memorizing many apparently isolated facts, is rote memorization, which plays an important role in the

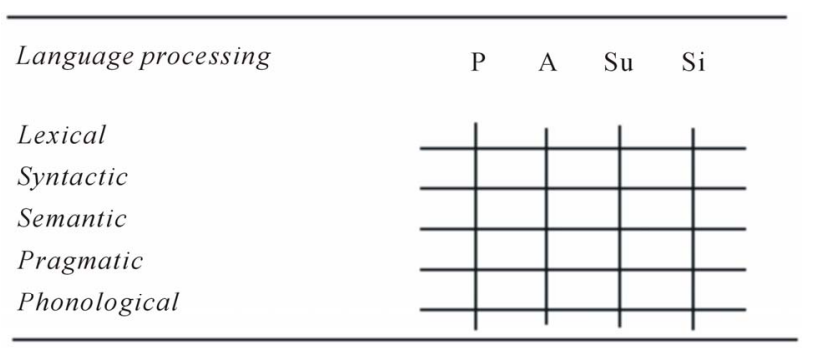

P: planning, A: attention, $\mathrm{Su}$ : successive,

Si: simultaneous

Figure 1.

PASS versus NON-PASS processing.

initial stages of learning. For instance, preschoolers often first learn to use numbers mechanically, or by trial-and-error problem solving, and then gradually discover or construct deeper and deeper understanding (insight). In PASS terms, rote memorization is mainly linked to successive processing.

Learning is a process of memorization, but meaningful learning is a different process from learning by rote memorization. Children may accurately imitate computational routines without understanding. Understanding is learning by insight. Insight requires thought. For instance, meaning of the plus sign $(+)$ or minus sign $(-)$ or times sign $(\times)$ or equals sign $(=)$ happens by connecting symbol to their concept. From the beginning, associations - relationships take place. In PASS terms, association is simultaneous. This way, thinking skill matures to reach deductive reasoning or the use of rules or principles to logically prove points. The discovery of relationships by examining cases characterizes inductive insight. In PASS terms, this operation implies planning.

Forming associations involves making connections with existing knowledge. Initially, the existing knowledge has to do with informal knowledge linked to personal experience. Informal knowledge is basically a concrete-tangible knowledge. Meaningful learning is necessarily dependent on what an individual already knows, and it takes place by relating the formal knowledge (symbolism, definition, and so on) to real knowledge (objects, things). Anyone is prone to forget information that is not personally meaningful. Thus, knowledge base becomes a reality. Therefore the role of memorized knowledge base is substantial for learning.

With development, children learn more relationships and their knowledge forms a more complete logical system (knowledge becomes more interconnected) to reason deductively, applying general abstracted principles or rules to solve specific problems. Children evolve from the simpler form of learning by rote memorization to more complex forms of learning and thinking (planning). Gradually, they are able to manage more cognitively complicated tasks. They reach a more advanced stage in thinking ability. For instance, counting backward is more difficult than counting forward for young children. Or at about 3 years children discover that higher count term is associated with larger magnitude. They realize that 2 not only follows 1 but also represents a larger quantity than does 1 . It is well known that language, weather verbal or written, is understood by the listener or reader according to the meaning shared by the transmitter and receptor of the language, something totally dependent on the frame of reference (knowledge base). Beliefs become an important part of knowledge base. 
In essence, relationship learning has to do with discriminating "same as" (equivalence) from "different from" (inequivalence). That's why discrimination is more difficult in cases of high similarity. The more defining characteristics that are shared, the more likely that a child o any person will confuse. For instance, for a child learning reading, letters like "f" and " $t$ " or "n" and "h", and "p" and "b" and "d". Also, numbers like 6 and 9. This discrimination is based on cognitive network higher complex than perceptual-motor network, which is involved in fine visual-motor integration processing responsible for the proper coordination of eyes and hand movements (Mesulam, 1998).

Another essential point has to do with the fact that the central-neurological processing happens more frequently unconsciously than consciously between the either consciously or unconsciously processed sensorial input (stimulus) and the either consciously or unconsciously processed output (response) (Das \& Kendrick, 1997; Das, Kar, \& Parrilla, 1996; Das, Naglieri, \& Kirby, 1994; Das, Garrido, Gonzalez, Timoneda, \& Perez-Alvarez, 1999; Davis et al., 2007, Perez-Alvarez \& Timoneda, 2007; Pujol et al., 2008 ). For instance, a child is presented with single separated letters, concretely, "u, b, s," (consciously processed input). He/she is asked to pronounce the successive combination "b, u, s," and he/she answers (output) correctly (consciously processed output). Then, he/she is asked to pronounce the presented sequence " $\mathrm{q}, \mathrm{u}, \mathrm{s}$," and the answer (output) is again $/ b \pi s /$. Incorrect answer, but incorrect reasoning ? If we ask him/her: "How did you do it?" He/she will answer : "I did it this way" (consciously processed output).

His/her explanation will be elaborated by his/her thinking brain taking via sensorial gates the information coming from outside in real time. In fact, it is a posteriori response to the answer being formulated. It is about a posteriori consciously thinking response with respect to the first previous unconscious mechanisms responsible for the resolution of the task. Probably, the verbal explanation being reported (consciously processed) will not correspond to the real reason for the response (unconsciously processed). Really, his/her unconsciously processed knowledge, not susceptible to be consciously and verbally reported, is the symbol " $b$ " sounds $/ b /$ whether right side up or not. Then, correct reasoning happened. If the same error in identification persists, we may shake our head in disbelief, unable to understand how the error could persist despite repeated correction (Bargh \& Ferguson, 2000; Dobbins, Schnyer, Verfaellie, \& Schacter, 2004).

Evaluation that exclusively examines resulting-external product is not accurate, and even may overestimate a child's competence in case of "false success" in academic learning. For instance, with a choice of only two answers to a question, you have a 50 - 50 chance of getting any particular question right just by guessing. On average, guessing should permit a pupil to get about 5 of the 10 correct. In fact, a correct response does not guarantee a deep appreciation of the rule, principle or knowledge. A focus on performance overlooks invaluable information needed to diagnose incomplete or inaccurate understanding or reasoning and to design an effective remedial plan. Errors provide important clues about underlying processes and the meaning of errors can disclose we are in the presence of a "false failure." Practically, we are always facing rule-governed learning. They may be logical, although incorrect.

Body language and, for instance, eye language may be very informative (Das, Kar, \& Parrilla, 1996; Das, Naglieri, \& Kirby,
1994; Das, Garrido, Gonzalez, Timoneda, \& Perez-Alvarez, 1999; Perez-Alvarez \& Timoneda, 2007). For instance, eyes up and to the left or to the right indicates simultaneous processing, eyes level and to the left or to the right successive processing, eyes down and to the left or to the right body sensations. And other body expressions are informative: wrinkled forehead, contracted jaw, shoulders thrown back, breading shallow in the chest, a fix grin, indicate all tension-concentration. On the contrary, shoulders relaxed and drooped breading deeply in abdominal area as breading from diaphragm indicate tranquility, relax. Therefore many body expressions tells us about cognition and emotion: unusual posture, specific hand movements, head turns, leaning to one side, rocking back and forth or side to side, rigid body, facial expression (mouth and eyebrows), startled look, big grin on the face, eye contact, yawning, particular words or phrases, voice quality and pitch, tone, volume, inflection, speed, tempo (rhythmic, choppy), and so on. We are not interested so much in what someone is saying as in how it is been said.

The learning based on facilitating rote memory by repetition is not an efficient one. A child may learn a procedure mechanically (rote memory/rotely memorized) but he/she does not really understand why the procedure woks. This is a non meaningful learning, a senseless procedure where the lack of relationships or associations does not makes far transfer possible and achievable. The new knowledge is not internalized to be used (far transferred) in a new task with no apparent relationship. The mechanical use of rotely learned procedures means that the rotely learned rules cannot transfer. Children fail to see any connection with a known procedure.

The more efficient learning is founded on minimizing successive processing (working memory/short term memory) and maximizing simultaneous processing (associations/long term memory) by tutored planning training (strategies/problem solving/decision-making). Indeed, tutored training is superior to non-tutored training, which is more linked to intuitive learning. The intuitive learning leading to intuitive knowledge fits into the existing pattern of thought. Young children, for instance, presented with a container with 5 items and another with 9 ones to which we add 4 and 2 more items respectively, think $5+4$ is "more than" $9+2$ because they saw "more" added to the first container. Clearly, intuitive arithmetic is imprecise, but the performance is coherent with the previous knowledge. Also, by observing that adding objects to a set "makes more", a child intuitively concludes that when a coin is added to a cup with five coins, that cup then contains more than a cup of eight to which nothing has been added. Or a child concluding that his longer row of 7 has more than his shorter row of 8 is using perceptual criterion of length to conclude that the longer row has more quantity. He/she must realize that the number of items in a set does not change because the appearance of the set has changed. The work of making the child internalize and transfer the new knowledge that substitute the old knowledge (change of knowledge) is the aim of an efficient intervention. The efficient intervention requires much more than just practice. Practice in itself does not guarantee learning.

According to neurological evidence, we know that signal transmission through synapsis is facilitated by the repetition of activity of the synapses (Guyton \& Hall, 1996). Since we know the long term potentiation phenomenon (Hebb, 1949), we also know that the effect of a stimulus becomes more potent when previous stimuli have been applied. Therefore repetition works 
by itself, but obviously temporal summation-rote memorization is a mental activity less efficient than global PASS mental processing. The spatial summation phenomenon must be considered neuronal expression of simultaneous processing. And conditioning is simultaneous processing and consequently learning may be considered as a conditioning phenomenon.

In fact, practice is important to make thinking skills automatic once learning took place. Empirical evidence indicates that the amount of practice (pointless drills, interviews, conversations) is not predictive of mastery. On the contrary, mastery is more directly linked to the development of meaningful knowledge than to practice frequency, although you'll learn by doing, by performing. It may take time to see, assimilate new information to what is known, and build up a network of relationships. Whereas some relationships are relatively easy to see and are quickly internalized (comprehension), others are not easily abstracted and require time to master. Children go at their own pace. Moreover, it is very frustrating for children to continue practicing when they can see that they are doing it incorrectly but do not know how to correct it.

Next, we will present an example of how PASS planning training (Das \& Kendrick, 1997) operates in order to get to construct or change a strategy. A child experiences that, for instance, $5-4=1 ; 8-7=1 ; 23-22=1$. The child may realize that the answer is always one. Then the rule: "the subtraction of two number neighbors produces a difference of one" can be internalized and transferred. The children can abstract a general rule or principle that enables them to respond efficiently even to previously unencountered problem (far transfer). Inductive learning works from the concrete and specific to the abstract and general. The abstract principle is to find something common to all the items. Abstraction is a question of degree such that the higher degree of abstraction is required for the higher cognitive concept.

We can use concrete procedures like blocks, fingers or marks for $5-2$. That is, for problems with addends of 5 or less, for instance, a finger-pattern procedure can be useful. So, for $3+5$, child puts up finger patterns of 3 and 5 on separate hands and then counts all 8 fingers. However, this strategy cannot be used with problems, such as $3+9$ and $4+10$. If so, another efficient mental computing procedure, the most economical mental procedure to minimize cognitive effort, is needed. A child may have no difficulty with $4 \times 2$ by doing four counted two times, but he may be overwhelmed by the problem $2 \times 4$ by doing two counted four times. He needs to see that $4 \times 2$ is equivalent to 2 $\times 4$, that is, that multiplication is commutative. When ready, children will abandon concrete procedures in favor of mental procedures. The child should be weaned from activities that rely on concrete objects (using concrete objects to compute the sum, for instance), visible clues (by pushing counted objects away into a clearly separate pile), and so on, and required to solve the problems mentally, gradually going from concrete to abstract representation, and running the bridge between concrete but limited direct perception and abstract but general ideas. Obviously, a concrete strategy becomes inefficient, even impossible, according to what is required.

Even children with learning difficulties can see ways of using their existing knowledge to shortcut cognitive effort, inventing more efficient workable strategies (planning), more powerful mental strategies (McCloskey, Caramaza, \& Basili, 1985; Shalev, Manor, Auerbach, \& Gross-Tsur, 1998). The same is true for very young or disadvantaged or mentally handicapped children.

In conclusion, we have discussed the process that explains the product, that is, our results. SLI, dyslexia, and dyscalculia are not homogenous entities in PASS terms. A kind of dyslexia is clearly defined by isolated successive weakness. SLI-expressive and a minority of both dyslexia and dyscalculia appear linked to successive weakness although associated with planning and additionally with attention in the case of SLI-expressive, which means these entities share common pathogenesis. SLI-expressive-receptive and Dyscalculia appear linked to simultaneous weakness, although associated with planning weakness. Other kind of SLIe-r appears linked to isolated planning weakness. Other types of SLIe-r and Dyscalculia appear liked to combined planning + successive + attention weakness. Therefore, SLIe-r and dyscalculia show higher heterogeneity. Isolated dysfunctional attention does not appear in any case. After 6 months of intervention, planning improves statistically in all cases. Efficient intervention is based on planning. Attention improves in few cases. Successive and simultaneous do not improve. The best result is in dyslexics and SLI-expressive and a minority of Dyscalculia. The worst result is in those without cognitive deficiency. SLIe-r and dyscalculia are in the middle. The effect of intervention at 6 months remains with minor changes at 12 months after 6 months without intervention.

This study has addressed some hypotheses regarding the diagnosis, treatment, and prognosis of cognitive function associated with learning difficulties. We anticipated what has been further elucidated and defined by this study concerning unexplored questions. It has provided valuable data and we hope the application of these results will be a step towards providing a better understanding of the topic. Likewise, we hope our results will stimulate significant further investigations into the field.

The most important limitations of this paper would be the sample size of some subsamples.

\section{Acknowledgements}

We thank the staff of the Fundació Carme Vidal de NeuroPsicoPedagogia for aid in the study and their care and interest in the investigation.

\section{REFERENCES}

Aldenderfer, M. S., \& Blashfield, R. K. (1984). Cluster analysis. Beverly Hills, CA: Sage Publications.

American Psychiatric Association (2000). Diagnostic and statistical manual of mental disorders (4th ed.). Washington, DC: APA.

Bargh, J. A., \& Ferguson, M. L. (2000). Beyond behaviorism: On the automaticity of higher mental processes. Psychological Bulletin, 126, 925-945. http://dx.doi.org/10.1037/0033-2909.126.6.925

Bishop, D. (1994). Is specific language impairment a valid diagnostic category? Genetic and psycholinguistic evidence. The acquisition and dissolution of language. Philosophical Transactions: Biological Sciences, 346, 105-111. http://www.jstor.org/stable/56025 http://dx.doi.org/10.1098/rstb.1994.0134

Bishop, D., \& Leonard, L. (2001). Speech and language impairments in children. Hove: Psychology Press.

Bravo, L. (1979). Cuestionario de evaluación de problemas de aprendizaje CEPA. Estudios Pedagógicos, 4, 113-123.

Cabeza, R., \& Nyberg, L. (2000). Imaging cognition II: An empirical review of 275 PET and fMRI studies. Journal of Cognitive Neuroscience, $12,1-47$. http://dx.doi.org/10.1162/08989290051137585

Catani, M., Jones, D. K., \& Fytche, D. H. (2005). Perisylvian language 
networks of human brain. Annals of Neurology, 57, 8-16. http://dx.doi.org/10.1002/ana.20319

Das, J. P., \& Kendrick, M. (1997). PASS reading enhancement program (PREP): A short manual for teachers. Journal of Cognitive Education, 5, 193-208.

Das, J. P., Kar, R., \& Parrila, R. K. (1996). Cognitive planning. The psychological basis of intelligent behavior. London: Sage Publications Ltd.

Das, J. P., Naglieri, J. A., \& Kirby, J. R. (1994). Assessment of cognitive processes. The PASS theory of intelligence. Massachussets: Allyn \& Bacon, Inc.

Das, J. P., Garrido, M. A., González, M., Timoneda, C., \& PérezÁlvarez, F. (1999). Dislexia y dificultades de lectura. Barcelona: Ediciones Paidós Ibérica SA.

Davis, M. H., Coleman, M. R., Absalom, A.R., Rodd, J. M, Johnsrude, I. S., Matta, B. F. et al. (2007). Dissociating speech perception and comprehension at reduced levels of awareness. Proceedings of the National Academy of Sciences of the United States of America, 104, 16032-16037. http://dx.doi.org/10.1073/pnas.0701309104

Dobbins, I. G., Schnyer, D. M., Verfaellie, M., \& Schacter, D. L. (2004). Cortical activity reductions during repetition priming can result from rapid response learning. Nature, 428, 316-9. http://dx.doi.org/10.1038/nature02400

Greicius, M. D., Krasnow, B., Reiss, A. L., \& Menon, V. (2003). Functional connectivity in the resting brain: A network analysis of the default mode hypothesis. Proceedings of the National Academy of Sciences of the United States of America, 100, 253-258. http://dx.doi.org/10.1073/pnas.0135058100

Guyton, A. C. \& Hall, J. E. (1996). Textbook of medical physiology (9th ed.). Philadelphia, PA: W.B. Saunders Company.

Hampson, M., Peterson, B. S., Skudlarski, P., Gatenby, J. C., \& Gore, J. C. (2002). Detection of functional connectivity using temporal correlations in MR Images. Human Brain Mapping, 15, 247-262. http://dx.doi.org/10.1002/hbm.10022

Le Bihan, D., Mangin, J. F., Poupon, C., Clark, C. A., Pappata, S., Molko, N., \& Chabriat, H. (2001). Diffusion tensor imaging: Concepts and applications. Journal of Magnetic Resonance Imaging, 13, 534-546. http://dx.doi.org/10.1002/jmri.1076

Maggiolo, M., \& Pavez, M. (2000). Test para evaluar los procesos fonológicos de simplificación (TEPROSIF). Santiago: Universidad de Chile.

Maldjian, J.A. (2001). Functional connectivity MR imaging: Fact or artifact? AJNR American Journal of Neuroradiology, 22, 239-240.

Matute, E., Rosselli, M., Ardila, A., \& Ostrosky-Solis, F. (2005). Evaluación neuropsicológica infantil. México: Universidad de Guadalajara.

Mc Crea, S. M. (2009). A review and empirical study of the composite scales of the Das-Naglieri cognitive assessment system. Psychology Research and Behavior Management, 2, 59-79. http://dx.doi.org/10.2147/PRBM.S5074

McCloskey, M., Caramaza, A., \& Basili, A. (1985). Cognitive mechanism in number processing and calculation: evidence from dyscalculia. Brain Cognition, 4, 171-196. http://dx.doi.org/10.1016/0278-2626(85)90069-7

Mesulam, M. M. (1998). From sensation to cognition. Brain, 121, 1013-1052. http://dx.doi.org/10.1093/brain/121.6.1013

Morgane, P. J., Galler, J. R., \& Mokler, D. J. (2005). A review of systems and networks of the limbic forebrain/limbic midbrain. Progress in Neurobiology, 75, 143-160. http://dx.doi.org/10.1016/i.pneurobio.2005.01.001

Naglieri, J. A., \& Das, J. P. (1997). Cognitive assessment system. Rolling Meadows, IL: Riverside Publishing.

Naglieri, J. A., \& Das, J. P. (1995). A reply to Kranzler and Weng's shooting in the dark. Journal of School Psychology, 33, 159-167. http://dx.doi.org/10.1016/0022-4405(95)00005-7

Pérez-Álvarez, F., \& Timoneda, C. (2007). A better look at intelligent behavior. Hauppauge, NY: Nova Science Publishers, Inc.

Perez-Alvarez, F., Fàbregas, M., \& Timoneda, C. (2009). Procesamiento cognitivo, fonémico o temporal? Neurologia, 24, 40-44.

Perez-Alvarez, F., Serra-Amaya, C., \& Timoneda-Gallart, C. (2009). Cognitive versus behavioral ADHD phenotype: What is it all about? Neuropediatrics, 40, 32-38. http://dx.doi.org/10.1055/s-0029-1231055

Pujol, J., Reixach, J., Harrison, B. J., Timoneda-Gallart, C., Vilanova, J. C., \& Pérez-Alvarez, F. (2008). Posterior cingulate activation during moral dilemma in adolescents. Human Brain Mapping, 29, 910-921. http://dx.doi.org/10.1002/hbm.20436

Raichle, M.E. (1991). Memory mechanisms in the processing of words and word-like symbols. Ciba Foundation Symposium, 163, 198-204.

Raichle, M.E.. (2000). A brief history of human functional brain mapping. In: Toga, A. W., \& Mazziotta, J. C. (Eds.), Brain mapping: The systems (pp. 33-75). San Diego, CA: Academic Press. http://dx.doi.org/10.1016/B978-012692545-6/50004-0

Rapin, I. (1998). Understanding childhood language disorders. Current Opinion in Pediatrics, 10, 561-566.

http://dx.doi.org/10.1097/00008480-199810060-00004

Rapin, I., \& Allen, D.A. (1983). Developmental language disorders: Nosologic considerations. In: U. Kirk (Ed.), Neuropsychology of language, reading and spelling. San Diego, CA: Academic Press.

Rosselli-Cock, M. E., Matute-Villaseñor, E., Ardila-Ardila, A., BoteroGómez, V. E., Tangarife-Salazar, G. A., Echeverría-Pulido, S. E., et al. (2004). Una batería neuropsicológica para la evaluación de niños con edades entre los 5 y 16 años. Un estudio normativo. Rev Neurol, 38, 720-731.

Sederberg, P. B., Kahana, M. J., Howard, M. W., Donner, E. J., \& Madsen, J. R. (2003). Theta and gamma oscillations during encoding predict subsequent recall. Journal of Neuroscience, 23, 10809-10814.

Shalev, R. S., Manor, O., Auerbach, J., \& Gross-Tsur, V. (1998). Persistence of developmental dyscalculia: What counts? Results from a 3-year prospective follow-up study. The Journal of Pediatrics, 133, 358-362. http://dx.doi.org/10.1016/S0022-3476(98)70269-0

Shinkareva, S. V., Mason, R. A., Malave, V. L., Wang, W., Mitchell, T. M., \& Just, M. A. (2008). Using fMRI brain activation to identify cognitive states associated with perception of tools and dwellings. Plos One, 3, e1394. http://dx.doi.org/10.1371/journal.pone.0001394

Swaiman, K. F., Ashwal, S., \& Ferriero, D. M. (2006). Pediatric neurology. Principles \& practice (4th ed.). Philadelphia, PA: Mosby Inc.

Swanson, L. W. (2007). Quest for the basic plan of nervous system circuitry. Brain Research Reviews, 55, 356-372.

http://dx.doi.org/10.1016/i.brainresrev.2006.12.006

Swanson, L. W., Grant, G., Hökfelt, T., \& Jones, E. G. (2007). Morrison JH. A century of neuroscience discovery: Reflecting on the Nobel Prize awarded to Golgi and Cajal in 1906. Brain Research Reviews, 55, 191-192. http://dx.doi.org/10.1016/j.brainresrev.2007.07.001

Tallal, P., Miller, S., \& Fitch, R. (1993). Neurobiological basis of speech: A case for the preeminence of temporal processing. Annals of the New York Academy of Sciences, 682, 27-47. http://dx.doi.org/10.1111/j.1749-6632.1993.tb22957.x

Vannest, J., Karunanayaka, P. R., Schmithorst, V. J., Szaflarski, J. P., \& Holland, S. K. (2009). Language networks in children: Evidence from functional MRI studies. American Journal of Roentgenology, 192, 1190-1196. http://dx.doi.org/10.2214/AJR.08.2246

Vuilleumier, P., \& Pourtois, G. (2007). Distributed and interactive brain mechanisms during emotion face perception: Evidence from functional neuroimaging. Neuropsychologia, 45, 174-194. http://dx.doi.org/10.1016/j.neuropsychologia.2006.06.003

World Health Organization (1993). International statistical classification of diseases and related health problems: Diagnostic criteria for research. Tenth Revision (ICD-10), Geneva: World Health Organization. 